\section{TEST MODULATOR OF AGS INJECTION FAST KICKER ${ }^{1}$}

\author{
W. Zhang, W.W. Frey, A.V. Soukas, S.Y. Zhang, and J. Bunicei \\ Brookhaven National Laboratory \\ Upton, New York 11973
}

DE90 015684

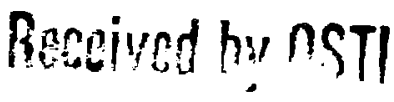

AUU 201990

\title{
ABSTRACT
}

In this paper, a test modulator of the Brookhaven AGS injection last kicker is described. The AGS injection kicker is the complementary system to the AGS Booster extraction last kicker. During the fourth batch transfer of the proton beam from the Booster to AGS, the fall time of the AGS injection kicker has to be very tast ( $<140 \mathrm{~ns}$ ), so that it does not appreciably deflect the first batch of injected protons that is circulating in the AGS. A test modulator was built, which consists of a PFN, a tail-biting section, and two thyratron switches. One thyratron switches the current to the load magnet, and another bites down the current at the end of the pulse. The load and circuit stray inductance is about $1.95 \mu \mathrm{H}$ to $2.15 \mu \mathrm{H}$, and the required peak current is about 1000 Amp. The current pulse waveform, tested at half curreat level ( $500 \mathrm{amp})$, has a fast fall time as well as a fast rise time. The test results will be presented, and some technical difficulties will be discussed.

\section{INTRODUCTION}

The Brookhaven AGS Booster, in its final phase of construction, will be completed this year. It will serve as a multi. function synchrotion injector for the AGS, capable of accelerating protons from $200 \mathrm{Mev}$, the Linac operating energy, to $1.5 \mathrm{Gev}$, at a repetition rate of $7.5 \mathrm{~Hz}$ (4 pulses/AGS pulse). The Booster is also capable of accelerating heavy ions to a magnetic rigidity equal to 17.52 tesla-meters, at a $1 \mathrm{~Hz}$ repetition rate ( 1 pulse/AGS pulse). Beam transfer from the Booster to the AGS will be bucket to bucket. There are $3 \mathrm{RF}$ accelerating buckets in the Booster, and 12 in the AGS. During each pulse of proton beam transfer, 3 Booster proton bunches will be transferred to 3 of 12 AGS buekets. At the final transfer, the fall time of the AGS injection kicker has to be very last (<140 as), so that it will not appreciably deflect the first bunch of the first injected Booster pulse. This means that the AGS kicker modules must incorporate some form of tail-biting circuit to reduce the kicker current fall time to meet the above requirement.

The AGS injection fast kicker, consisting of 3 identical modules, will be located at the A5 straight section of the AGS ring. Its required strength is to deflect the $1.5 \mathrm{Gev}$ (rigidity $B \rho$
$=7.51 \mathrm{~T}-\mathrm{m}$ ) prown beam by $3 \mathrm{mrad}$, and the $11 \mathrm{~T}-\mathrm{m}$ rigidity heavy ion beam by $3 \mathrm{mrad}$. The kicker magnet is 3 lumped inductance picture frame type. The load magnet and loop seray inductance is estimated at $1.95 \mu \mathrm{H}$ to $2.15 \mu \mathrm{H}$ for each module. The pulser parameter specifications are listed in Table 1 .

Tuble 1 - PULSER PARAMETER SPECIFJCATIOI:

Proton Heavy Jon

$\begin{array}{lll}\text { Rise time } & 120 \mathrm{~ns}(0-07 \%) & 160 \mathrm{~ns}(0-08 \%) \\ \text { Pulse length } & 600 \mathrm{~ns} & 1000 \mathrm{~ns} \\ \text { Fall time } & 120 \mathrm{~ns}(07 \%-10 \%) & <2300 \mathrm{~ns} \\ \text { Pulse overshoot } & 3 \% & 2 \% \\ \text { Flat top ripple } & <3 \% & <2 \% \\ \text { PFN voltage } & 401 \mathrm{VV} \max & -40 \mathrm{KV} \max \\ \text { Peak current } & 1006 \mathrm{~A} & 1473 \mathrm{~A}\end{array}$

\section{SYSTEM DESCRIPTION AND TEST RESULT}

Since the AGS injection fast kicker is the complenentary system to the AGS Booster extraction fast kicker, some requirements, such as the ability to operate for both proton

1 Work performed under the auspices of the U.S. Department of Energy.

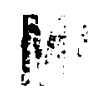


and heavy ion beam transfer with fast rise lime and limited voltage for reliabie operation in air, are the same for both kickers. Therefore, a similar pulse front shaping network is used for both kicker systems. To meet the different kicker current requirements of proton and heary ion injection, a resistor is switched to match or mismatch the puise forming network impedance. Two R-C compensators are used to obtain a last pulse rise time, one in parallel with the matching resistor is a sink network, and another in parallel with the first PFN capacitor is an energy compensation network. Detailed discussion of the pulse front shaping is given in reference [2], and the current testing results of the B3 (Booster extraction fast kicker) prototype module are shown in photographs 1 and 2.

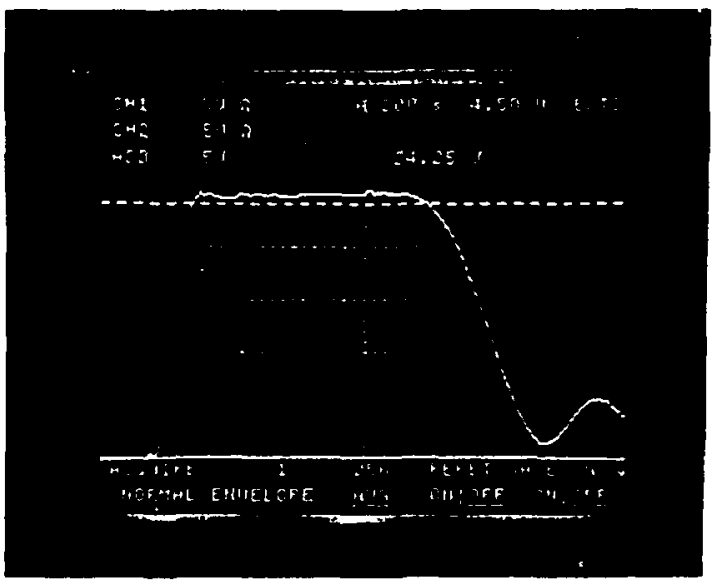

Photograph 1. Current Waveform

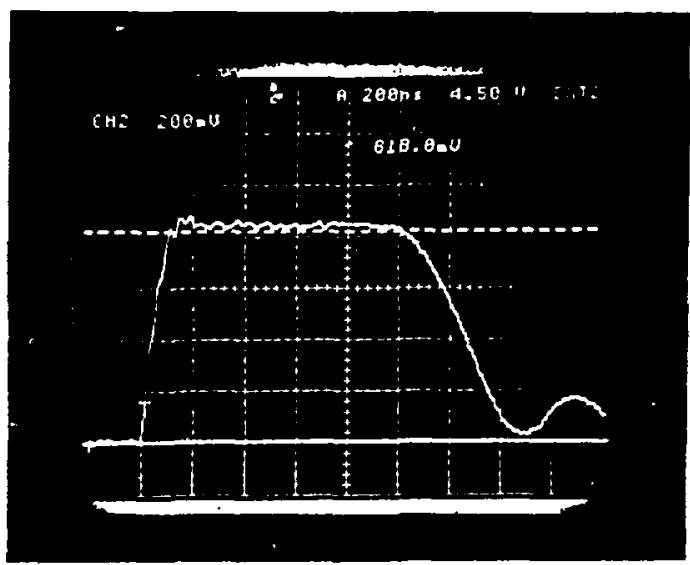

Photograph 2. Field Waveform
The main additional requirements of the AGS injection last kicker are a last lall time for proton beam injection, and a longer pulse width for heavy ion injection. This fast fall time specification is very stringent for a low cost high inductance lumped magnetic kicker. The decision to build this type magnet was made based on budgetary concerns, manpower availability, and project schedule etc., and after we studied and evaluated the schematics such as the CERN traveling wave kicker [3], HCTF EMD injection pulser [A] etc. A test circuit shown in Figure 1, improved from a schematic in [4], is chosen because of its structural simplicity and promising perfortuance. A test pulser based on this circuit has been simulated. constructed, and tested. Photograph 3 shows this test pulser. The EEV CX1154 thyratrons were used as the main switch as well as the tail-biting switch.

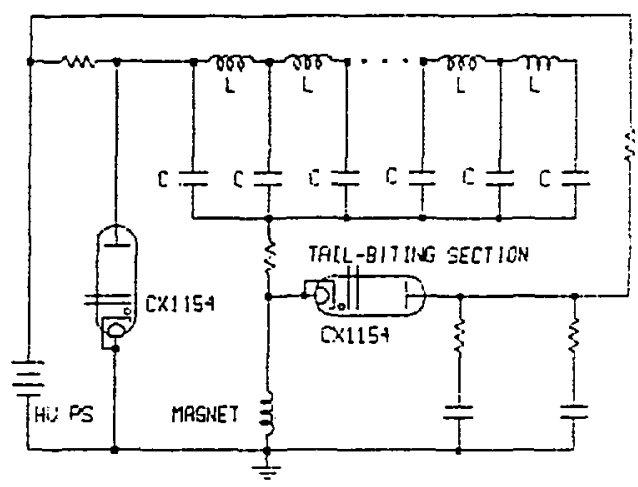

FIGURE 1. IFST OULSER

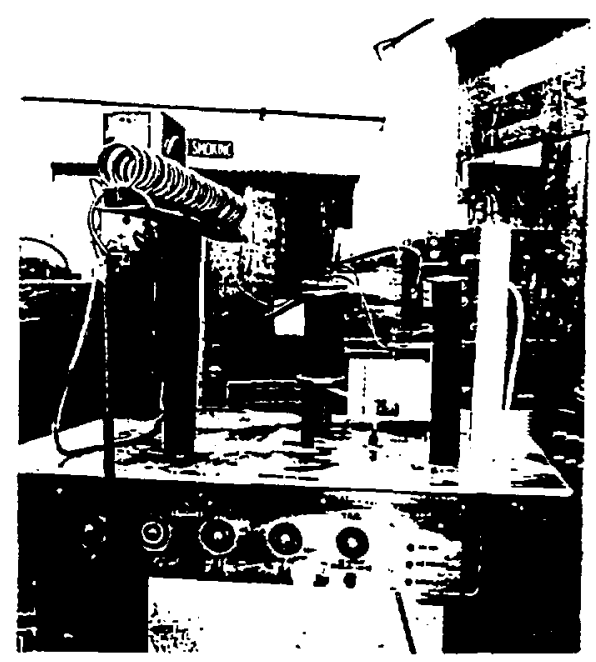

Fhutograph 3. Tėt Fuletr 
In the construction of this test unit, both thyratron assemblies have been carefully shielded and arranged on different sides of the PFN to eliminate pulse coupling. The compact package of the tail-biting thyratron auxiliary power supply kept the effects of the distributed inductance and capacitance as low as possible. This test unit has been powered up to $25 \mathrm{KV}$, and about $900 \mathrm{~A}$ including the tail-biting function.

To increase the current pulse tail-biting speed, a separate power supply is used to charge up the tail-biting section capacitors. With a higher tail-biting voltage, a trapezoidal current pulse is obtained. The fall time of the current pulse is comparable to the rise time. Due to the voltage rating of the CX1154 thyratron and power supply limitation, the pulser was tested at $500 \mathrm{~A}$. For each PFN tested, there is a nearly optimum point of time to bite down the current. As the tailbiting point shifts, the results of the current fall time and percentages of undershoot could be very different. Some teat results are shown in photographs 4 and 5.

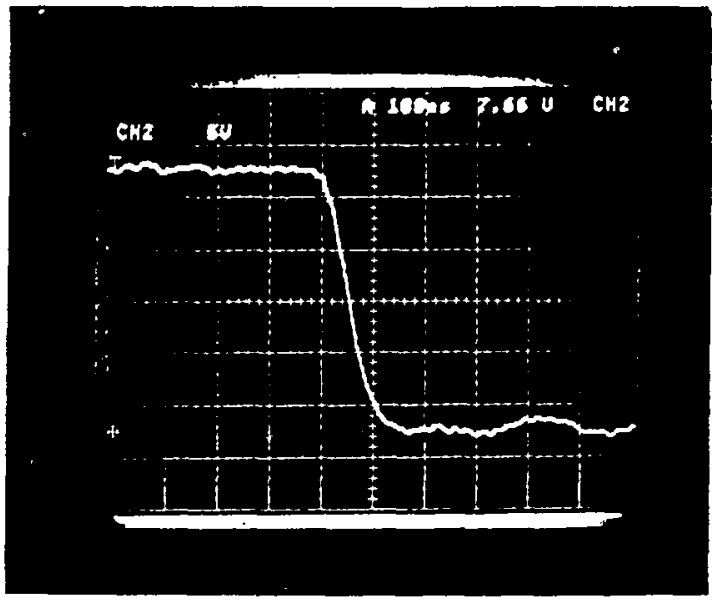

Photograph 4. Pulse fall time with $t=600$ ns

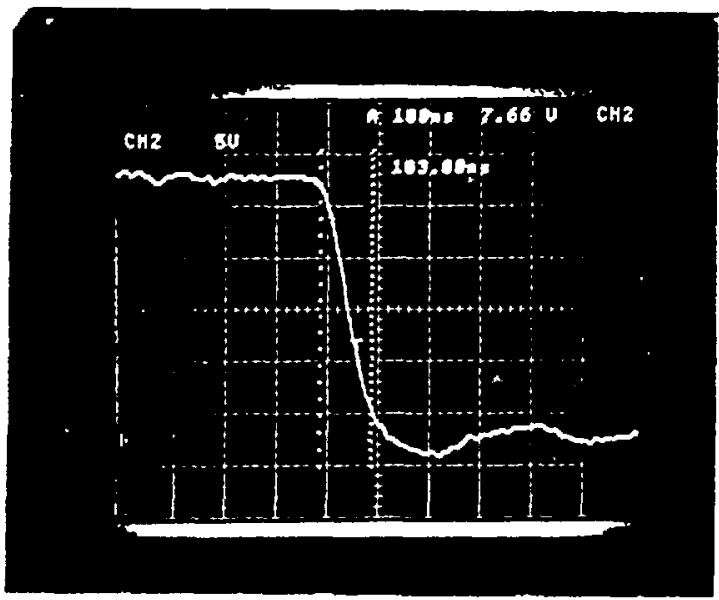

Photograph 5. pulse fall time with $t=616 \mathrm{hs}$
The design of the tail-biting function of the AGS injection fast kicker is based on the above mentioned test unit. Two gap thyratrons are used to hold-off higher voltages, and a double ended tube is placed as the main switch to allow bi-directional current flow for heavy ion injection. The prototype AGS injection fast kicker modulator has been constructed, as shown in Figure 2 and photograph 6 . Two more modules are in the construction phase, making a total of 3 modules.

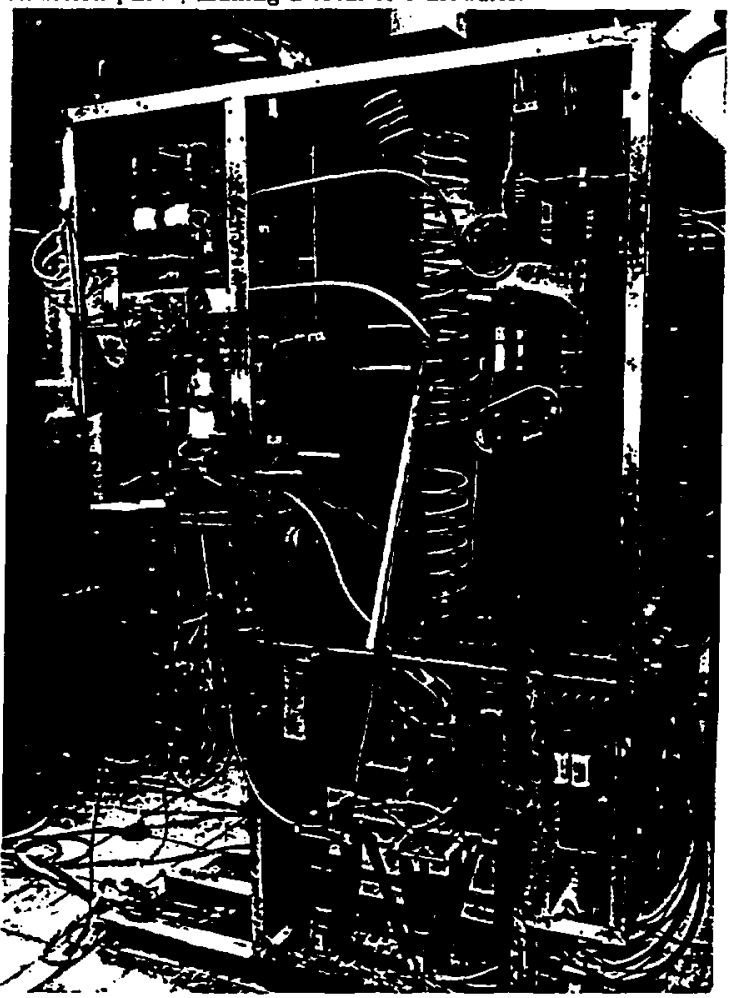

Photograph 6, AGS Injection Kicker Prototype Modulator

The main switch thyratron is triggered to start the pulse. Approximately 720 ns later, the tail-biting thyratron is triggered to cut off the current pulse. At the beginning of tire rising part of the pulse, the current through the load magnet and the matching resistor is zero, so the voltage across the magnet inductance is about the full PFN voltage. Therefore, the tailbiting tube at this moment is holding off a high voltage equivalent to the summation of the tail-biting capacitor voltage and at least half of the voltage the PFN is charged to. The catbode plate of the tail-biting thyratron is connected to the high voltage end of the magnet (see Figure 2). During the pulse rise, the cathode plate and auxiliary grid power supplies of the tail-biting thyratron will loat to a aegative high voltage. The transient of this high voltage introduces noise to the triggering circuit that might cause the tail-biting thyratron to mis-trigger. At the late portion of the pulse fat cop region, the tail-biting thyratron is triggered. The voltage to whilh the tail-biting capacitors are charged is then applied to the load 
magnet to force a fast decrease of the current. The current fall rate is governed by $\frac{d i(t)}{d t}=\frac{v(t)}{L}$, which is proportional to the voltage that the tail-biting capacilor is charged to. The function of the tail-biting voltage is to force a fast extraction of the inductive energy stored in the magnet and to dissipate in the resistors both the capacitive and inductive energies stored. During the pulse flat top, the voltage across the matching resistor is half of the PFN voitage. When tail-biting is applied, the voltage acrossing the matching resistor jumps to the sum of half of the PFN voltage and the tail-biting voltage. The high current passing through the matching resistor dissipates most of the stored energies. The sink R-C compensator in parallel with the matching resistor bypasses a part of the current during the current pulse fall region and reduces the resistive loss. Although a higher tail-biting voltage will guarantee a faster current fall time, device limitations and other design considerations, such as thyratmn forward and reverse voltage ratings and pulse undershoot etc., favor a lowe- tailbiting voltage at a comparable level of the PFN charging volcage. To reach a fast curreal fall time will limiled tail-liting voltage, a multiple section R-C network will perform much better than a single section capacitor. Other benefits of the multiple section R-C network are the lower undershoot and a wider tail-biter triggering range at a non-optimal triggering time.

Although a diode has been placed in series with the load magnet, at present it is shorted out. It will be activated to attempt wo clean up the pulse undershoot and the tail ripples, when a modified auxiliary power supply and triggering unit are ready. The major technical difficulty is the implementation of the auxiliary grid supplies and triggering circuit of the tailbiting thyratron. The device internal inductance, distr"buted inductance and capacitance have turned out to be crurial to the tail-biting circuit stability. Since the auxiliary circuit of the tail-biting thyratron will float at negative high voltage during the current pulse rise, the transient noise coupled by device and distributed inductance and capacitance might prematurely trigger the thyratron or cause a tail-biting time jitter problem. The A-5 prototype module has been powered up to $25 \mathrm{KV}$ for proton operation testing, and an unstable performance of the tail-biter triggering circuit has been observed above $20 \mathrm{KV}$. The tail-biter was in a seil trigger type mode. Mennwhile a tailbiting test has been performed successfully at half current level (500A) using this module. The modification of the triggering circuit is underway.

A floating deck trigger anplifier is used to pulse the tailbiting swilch tube grid. Due to the fast rate of rise of eturrent in the magnet load, it is necessary to isolate the tail-biting control grid circuit from transients and noise. A small hard tube modulator, utilizing a planar triode (6442 lube type) referenced to the tail-biting tube cathode is used. A $1: 4$ pulse transformer is used to trigger the tail-biting switch lube. The trigger is coupled up to the floating deck using a IV/A Pearson current transformer with a 3 turn primary at ground reference A $1500 \mathrm{~V}$ trigger pulse into 50 ohms is developed as the tail-biting trigger. The $80 \mathrm{~V}$ pulse on the current transformer output drives the grid of the 6442 well into the positive grid/emission limited region from the hard cut-off region. Stray capacitance of the trigger circuit is minimized to allow stable triggering.

Some test results of the A5 prototype module are shown in photographs 7 and 8. The PFN impedance is about $14 \mathrm{ohm}$. A $14 \mathrm{KV}$ charging voltage was applitd to the PFN, anil the tail-biting voltage used was $18 \mathrm{KV}$. The photos show the load inductor current pulse of $500 \mathrm{~A}$ peak with fast rise and fall time. The fall time from fiat top level to $10 \%$ is about $120 \mathrm{~ns}$, and the tail ripple is about $5.8 \%$. The comparison of the pulse with and without tail-biting are shown is photographs 8 and 8.

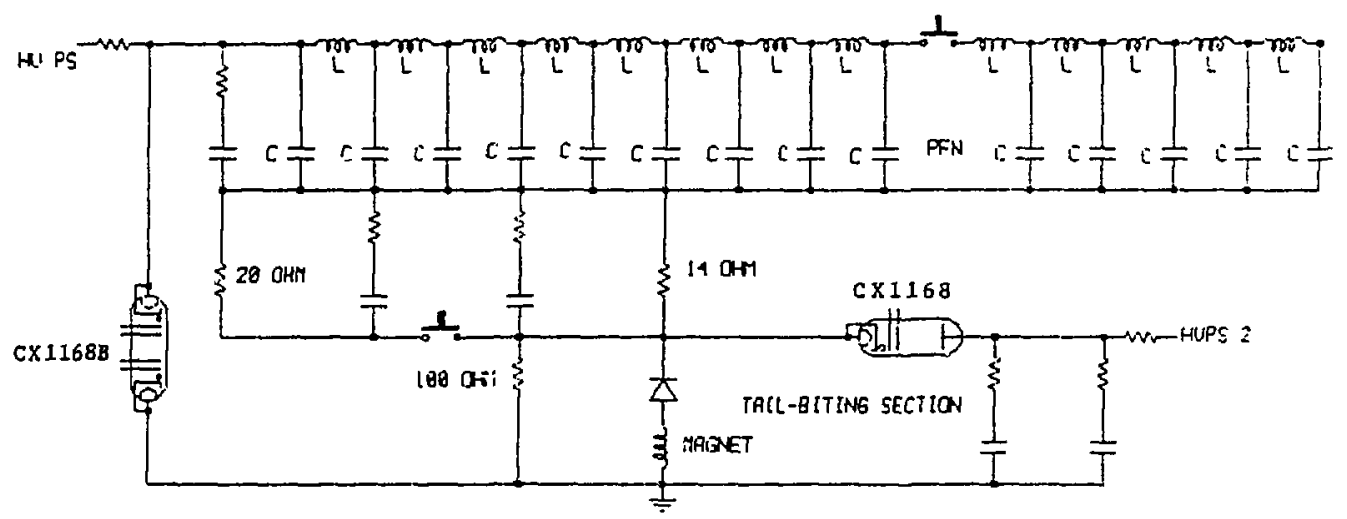

FIGURE 2. AGS IN.JFCTION KICKER POLEA SIPFLY SCIFIRTIC 


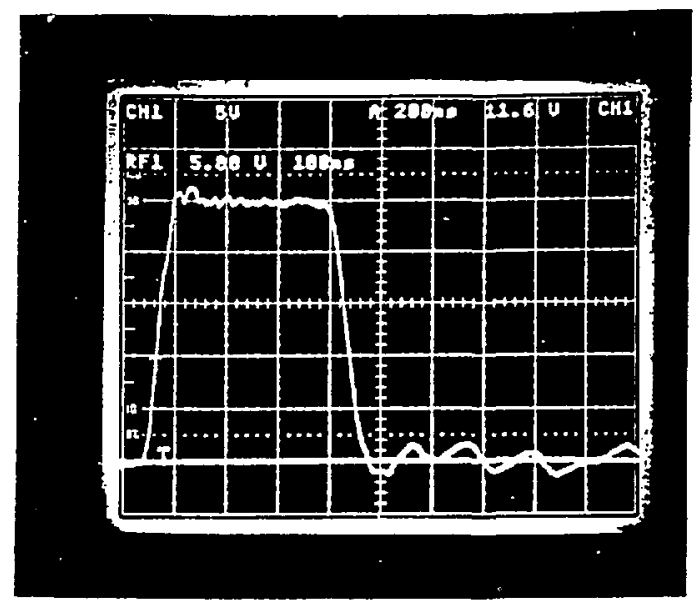

Photograph 7. Pulse Waveform

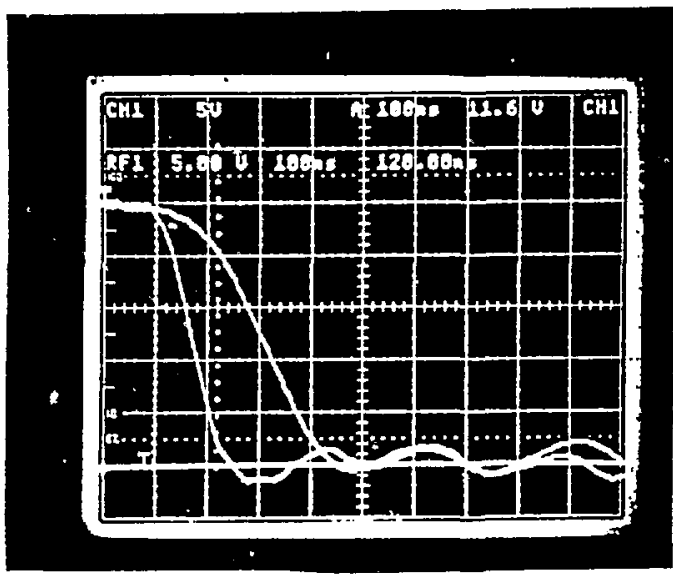

Photograph 8. Pulse fall times with and without tail-biting

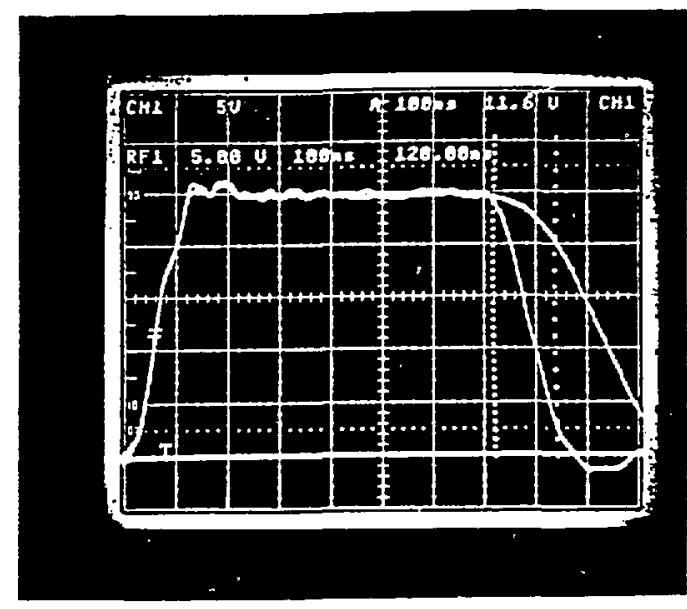

Photograph 9 . Pulse Waveforms with and without tali-biting

\section{REFERENCES:}

1. "Bnoster Design Manual", AGS Booster Project, AD Department, Brookhaven National Laboratory, 1988.

2. W. Zhang, et al., "Test Fast Kicker pulser", Proceedings of 7th Pulsed Power Conference, 1988.

3. E. Frick, et al., "Fast Pulsed Magnet Systems for Proton and Antiproton Injection into the CERN $400 \mathrm{GeV}$ Proton Synchrotron", IEEE Conference Record of 1882 Fifteenth Power Modulator Symposium, 1982.

4. J. Pachner, Jr., "A Pulsed Ferrite Inflector for the Emittance Measuring Device of the Chalk River High Cursen: Test Facility", Proceedings, 1873 Particle Accelerator Conference, 1973.

5. J. P. O'Loughlin and L. J. Sidler, "The End of Line Tail Biter", Proceedings of 6 th Pulsed Power Conference, 198 .

\section{DISCLAIMER}

This report was prepared as an account of work sponsored by an agency of the United States Government. Neither the United States Government nor any agency thereof, nor any of their employees, makes any wurranty, express or implied, or assumes any legal liability or responsibility for the accuracy, completeness, or usefulness of any information, apparatus, product, of process disclosed, or represents that its use would not infringe privately ouned rights. Reference herein to asy specific commercial product, process, or service by trade name, trademark. manufacturer, or otherwise does not necessarily constitute or imply its endorsement, recommendation. or favoring by the United States Government or any agency thereof. The views and opinions of authors expressed herein do not necessarily state or reflect those of the United States Government or any agency thereof. 